\title{
Intimate Partner Violence, Welfare Receipt, and Health Status of Low-Income African American Women: A Lifecourse Analysis
}

\author{
Mieko Yoshihama, ${ }^{1,3}$ Amy C. Hammock, ${ }^{1}$ and Julie Horrocks ${ }^{2}$
}

Published online: 18 February 2006

\begin{abstract}
Although the association among intimate partner violence (IPV), welfare receipt, and health status has been well-established, little is known about the temporal sequencing of these events. In a random sample of low-income African American women in an urban Midwestern county, lifecourse data about IPV and welfare receipt were obtained using the Life History Calendar method (D. Freedman, A. Thornton, D. Camburn, D. Alwin, \& L. YoungDeMarco, 1988), along with data about mental and physical health status. Controlling for relevant factors, longitudinal analyses found that previous experience of IPV increased women's odds of receiving welfare benefits in a given year, but previous welfare receipt did not. $\mathrm{Cu}$ mulative IPV, but not cumulative welfare receipt, was associated with current and past-year health problems. These findings are consistent with the hypothesis that IPV leads women to turn to welfare assistance, and that compromised physical and mental health due to past cumulative IPV interferes with women's gainful employment.
\end{abstract}

KEY WORDS: intimate partner violence; health; mental health; welfare; lifecourse.

The nested ecological model (Bronfenbrenner, 1979) has been used to understand the relationships among the multiple and interacting personal, situational, and sociocultural factors that contribute to women's experiences, such as intimate partner violence (IPV), welfare receipt, and poor health (Brownridge \& Halli, 2002; Green, Richard, \& Potvin, 1996; Heise, 1998; Kneipp, 2000; Stokols, 1996). According to this framework, various health problems, for example, are understood to result from multiple factors at the ontogenic, micro-, mezzo-, and macro-levels of the human ecology. Less explored in the literature, however, has been the way that time (or, in Bronfenbrenner's terms, "the chronosystem")

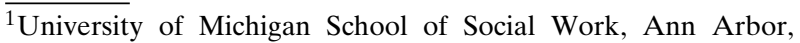
Michigan.

${ }^{2}$ Department of Mathematics and Statistics, University of Guelph, Guelph, Ontario, Canada.

${ }^{3}$ To whom correspondence should be addressed at University of Michigan School of Social Work, 1080 S. University, Ann Arbor, Michigan 48109-1106; e-mail: miekoy@umich.edu.
}

impacts the complex relationships among these factors.

Despite the documented high prevalence of IPV among low-income women (Tjaden \& Thoennes, 2000), particularly women on welfare (Riger \& Krieglstein, 2000; Tolman \& Raphael, 2000), little is known about the temporal relationship between IPV and welfare receipt. Therefore, it remains unclear whether the experience of IPV precedes financial vulnerability and welfare receipt, or vice versa. Using a specialized methodology, the Life History Calendar (LHC) method (Freedman, Thornton, Camburn, Alwin, \& Young-DeMarco, 1988), we obtained lifetime data from respondents on the timing of IPV and welfare receipt, in order to examine the effect of cumulative IPV on subsequent welfare receipt and the effect of cumulative welfare receipt on subsequent experience of IPV. In addition, given that both low income and history of IPV are risk factors for compromised physical and mental health (Browne, Salomon, \& 
Bassuk, 1999; Campbell, 2002; Kessler et al., 1994; Tolman \& Rosen, 2001), we investigated to what extent cumulative exposure to IPV and cumulative welfare receipt independently or interactively affect women's current health status.

\section{Welfare Receipt and Experience of IPV}

Low-income women report higher rates of IPV than women of other socioeconomic groups (Rennison \& Welchans, 2000; Sutherland, Sullivan, \& Bybee, 2001), and studies suggest that rates of IPV are higher among women on welfare than among other low-income women (Honeycutt, Marshall, \& Weston, 2001; Raphael, 2002; Tolman \& Raphael, 2000). Lifetime prevalence rates of physical IPV for women on welfare range from 29 to $74 \%$ (Barusch, Taylor, \& Derr, 1999; Colten, Cosenza, \& Allard, 1996; Lloyd \& Taluc, 1999; Tolman \& Rosen, 2001), whereas lifetime prevalence rates of physical IPV in the general population range from 22 to $31 \%$ (Collins et al., 1999; Klein, Campbell, Soler, \& Ghez, 1997; Straus \& Gelles, 1990; Tjaden \& Thoennes, 2000). Studies also suggest that women on welfare are particularly vulnerable to severe IPV, such as having been punched, kicked, and/or threatened with a weapon (Bassuk et al., 1996; Lloyd \& Taluc, 1999).

Intimate partner violence makes it difficult for women on welfare to seek, obtain, and maintain employment (Lloyd \& Taluc, 1999), which, in turn, makes it difficult for them to adhere to work requirements outlined by the 1996 Personal Responsibility and Work Opportunity Reconciliation Act (PRWORA) (Cole, 2001; Raphael, 2002; Riger \& Krieglstein, 2000; Tolman \& Raphael, 2000). Abusive partners use a combination of tactics to sabotage women's employment possibilities, such as destroying homework assignments, turning off alarm clocks, tearing clothing, physically injuring women in visible areas (such as the face), not following through on agreed-upon childcare arrangements, and harassment on the job (Moore \& Selkowe, 1999; Raphael, 2002; Tolman \& Raphael, 2000). This type of work interference may be a reason why women who have experienced IPV are more likely than nonabused women to cycle on and off welfare multiple times (Cole, 2001). To address the barriers that abused women face, many states have adopted the Family Violence Option (FVO) and similar measures, which allow women to apply for exemptions to PRWORA work requirements if they feel that these require- ments will put them at greater risk for IPV. However, most eligible women do not apply for the FVO (Lein, Jacquet, Lewis, Cole, \& Williams, 2001; Raphael, 2002); therefore, the impact of this exemption is limited.

\section{Welfare Receipt and Health Status}

It is well established that low-income individuals, especially the persistently poor (i.e., individuals who earn less than $\$ 20,000$ for 4 years or more), have high rates of mortality and morbidity (Geronimus, 1992; Krieger, Rowley, Herman, Avery, \& Phillips, 1993; McDonough, Duncan, Williams, \& House, 1997; Ren, Benjamin, \& Williams, 1999; Sorlie, Backlund, \& Keller, 1995). Studies have also found an association between low income and compromised mental health among women, such as affective disorders, anxiety disorders, and nonaffective psychosis (Fryers, Melzer, \& Jenkins, 2003; Kessler et al., 1994; Regier et al., 1993; Robbins, Locke, \& Regier, 1991; Williams, Takeuchi, \& Adair, 1992). However, it is only recently that researchers have studied the connection between poor health and welfare receipt specifically (Lennon, Blome, \& English, 2002).

Recent studies that specifically examined the health of welfare recipients suggest that women on welfare may be particularly at risk for compromised health (Danziger et al., 2002; Horwitz \& Kerker, 2001; Polit, London, \& Martinez, 2001; U.S. General Accounting Office, 2001). Analyses from the 1994 1995 National Household Survey of Drug Abuse show a statistically significant difference in rates of depression between single mothers on welfare and single mothers not on welfare ( 12 vs. $8 \%, p<0.01)$. Longitudinal analysis of a random sample of welfare recipients in Michigan (Corcoran, Danziger, \& Tolman, 2004) found that $70 \%$ of respondents reported limitations in physical functioning, $45 \%$ met the diagnostic screening criteria for major depression, and $35 \%$ met the diagnostic screening criteria for posttraumatic stress disorder (PTSD) in one or more waves of data collection-higher rates than national prevalence estimates (Kessler et al., 1994; Kessler, Sonnega, Bromet, Hughes, \& Nelson, 1995).

\section{IPV and Health Status}

Population-based and clinical studies have consistently found acute and long-term mental and 
physical health problems in women who have experienced IPV: e.g., lower self-rated health status, higher symptom levels; increased physical limitations, chronic pain, decreased productivity, and increased health services use (Campbell et al., 2002; Campbell \& Soeken, 1999; Coker, Smith, McKeown, \& King, 2000; Collins et al., 1999; Golding, 1999; McCauley et al., 1995; Sutherland et al., 2001). The mental health consequences of IPV, particularly PTSD and posttraumatic stress symptoms, have also been documented extensively. For example, studies in the United States have found that 30$84 \%$ of women who have experienced IPV suffer from PTSD (Cascardi, O'Leary, \& Schlee, 1999; Kemp, Rawlings, \& Green, 1991; Saunders, 1994; Yoshihama \& Horrocks, 2003). These rates are much higher than the $10-14 \%$ rate of PTSD among women in the general population (Breslau \& Davis, 1992; Breslau, Davis, Peterson, \& Schultz, 1997; Kessler et al., 1995; Resnick, Kilpatrick, Dansky, Saunders, \& Best, 1993).

\section{Welfare Receipt, IPV, and Health Status}

Studies suggest that low-income women who experience IPV may be particularly vulnerable to poor physical and mental health outcomes. In a community sample of women from all income levels, low-income women who had experienced physical IPV within the past six months reported significantly poorer physical health symptoms than abused women of other income levels (Sutherland et al., 2001). Among a community sample of low-income women, those who reported having experienced IPV in the past 12 months were significantly more likely than women who had not been abused during that time period to have been hospitalized for physical problems and/or mental health issues in the past year (Browne et al., 1999). In a longitudinal study in Michigan, female welfare recipients who had experienced past-year IPV were twice as likely to have received treatment for mental health problems in the past 12 months and more than three times as likely to report a current need for mental health treatment compared to never-abused women (Tolman \& Rosen, 2001). In a sample of welfare recipients in Pennsylvania, women who reported experience of IPV in their current or most recent relationship were more likely than nonabused women to have at least three posttraumatic stress symptoms (Brush, 2000).

\section{Putting It All Together: An Ecological Lifecourse Approach to Studying Welfare Receipt, Experience of IPV, and Health Status}

Nested ecological theory indicates a complex, multilayered relationship between recent IPV, welfare receipt, and health status. While this relationship has been examined in cross-sectional and longitudinal studies (Browne et al., 1999; Sutherland et al., 2001; Tjaden \& Thoennes, 2000; Tolman \& Rosen, 2001), associations among lifetime welfare receipt, lifetime experience of IPV, and current health status have been examined less. The temporal relationship between welfare receipt and IPV remains unknown. One of the reasons for this lack of data is that cumulative exposure to IPV is difficult to measure. IPV is often recurrent and persistent; women may experience IPV from multiple partners over their lifecourses (Burgess et al., 1997; Sherman et al., 1991; Tjaden \& Thoennes, 2000; Yoshihama \& Gillespie, 2002). Several studies have found a strong positive association between the frequency and duration/chronicity of violence and the severity of psychological distress among battered women (Astin, Lawrence, \& Foy, 1993; Gelles \& Harrop, 1989; Kemp et al., 1991). Despite the possibility that some women may have been victimized by more than one partner, many studies have focused exclusively on past year or most recent victimization, thereby failing to assess the effects of prior IPV. Other studies have focused on whether the respondent had ever experienced IPV at some time in the past without obtaining information on the timing, duration, or frequency of IPV over the lifecourse.

In this study, we addressed such difficulties in data collection and analysis by employing a unique methodology, the Life History Calendar (LHC) (Freedman et al., 1988), to obtain lifetime data on women's experience of IPV and welfare receipt. The LHC method facilitates recall of significant events over the lifecourse through the use of its unique calendar format. The lifecourse data obtained via the LHC method permitted the use of longitudinal data analysis techniques to investigate the relationship between welfare receipt and IPV while accounting for their relative temporal sequence. Specifically, we tested whether past IPV was associated with subsequent welfare receipt, and whether past welfare receipt was associated with subsequent IPV. In addition, we assessed whether compromised health status was associated with cumulative IPV, cumulative welfare receipt, or both. 


\section{METHODS}

\section{Sampling}

The respondents were selected randomly from a list of female welfare recipients in a large urban county in a Midwestern state who met the following criteria: aged 18-54, of African American or Caucasian descent, were United States citizens, and spoke English. Approval for the study was obtained from the state welfare agency, which provided the list, as well as the Institutional Review Board of the first two authors' university. Following an introductory letter, a trained interviewer contacted each selected household in person or by telephone. Of the 156 households in which the interviewer made contact with a resident, no eligible individual was found in 25 households, and in 74 households, the interviewer was not able to speak to an eligible woman. Of the remaining 57 households, 42 women completed a face-to-face interview, which consisted of two parts: the LHC (see below) and a structured interview schedule that assessed health status and sociodemographic characteristics.

Of the 42 respondents, 40 identified themselves as African American, and the other two identified themselves either as White or biracial. Previous studies have found significant differences in the rates of IPV among women of different racial backgrounds (Sorenson, Upchurch, \& Shen, 1996; Straus, Gelles, \& Steinmetz, 1980; Tjaden \& Thoennes, 2000). Because of the extremely small number of non-African American respondents, the 40 women who identified themselves as solely African American were included in the analyses.

\section{Data Collection Procedures}

Two female interviewers were recruited for this study from a pool of trained interviewers at a survey institute of the first two authors' university. Prior to the beginning of data collection, they participated in one-and-one-half days of training, which focused on the administration of the LHC interview. The project staff reviewed the first five interviews of each interviewer and provided detailed verbal and written feedback. In addition, weekly conference calls were held to discuss and trouble-shoot interview administration for the first 2 months and less frequently afterwards. Approximately one-and-one-half months after data collection began, a follow-up training meeting (one half day) was held. Throughout the study period, a clinical social worker with expertise in mental health surveys was available for respondents and interviewers to provide assistance in dealing with distress and other emotional difficulties that they might experience.

Interviewers obtained written informed consent at the beginning of each interview, and the interview was audiotaped with a separate consent. Each respondent received $\$ 20$ and a list of assistance programs at the end of the interview. The average length of the interviews was $86.4 \min (S D=30.4$, range 45-200).

\section{The Life History Calendar}

We used the LHC method (Freedman et al., 1988) to collect information about lifetime experiences of IPV, welfare receipt, and other life events. Using a semistructured interview schedule in conjunction with a physical calendar, the LHC method first elicits information about memorable and/or easily recalled events (e.g., births, deaths, geographic mobility, employment history) that is then used to help in the retrieval of less easily recalled information (e.g., experiences of IPV) (Freedman et al., 1988; McPherson, Popielarz, \& Drobnic, 1992).

The LHC is designed to effectively use the idiosyncratic cues available in the structure of autobiographical memory and provides multiple retrieval pathways (Belli, 1998; Belli, Shay, \& Stafford, 2001). In addition to using the top-down construction employed in most survey instruments by ordering questions from general to specific, the LHC method facilitates "sequencing" retrieval and "parallel" retrieval. The former pathway involves recalling events within a certain theme that are temporally associated together, often in a forward or backward chronological order. For example, when asked about her lifetime experience of IPV, a woman might describe how one partner's abuse escalated over time. The latter pathway, parallel retrieval, involves remembering contemporaneous events across related thematic domains. For example, a woman might remember her partner's abusive act as having occurred during the same month as her father's death and the start of her new job. Using multiple retrieval pathways, the LHC method facilitates the respondent's recall of past life events. Two empirical studies found that respondents tended to remember past events more accurately when interviewed in the LHC method compared to a structured interview (Belli et al., 2001; 
Yoshihama, Gillespie, Hammock, Belli, \& Tolman, 2005). This was especially true of events that occurred in the remote past. An additional advantage of the LHC method is that recording the occurrence and sequence of events in a familiar calendar format makes it easier to assess consistency and address any discrepancies in the reported timing of events during the interview. This feature of the LHC method was particularly important in assessing and recording IPV and welfare receipt, which are often recurrent with varying duration.

During the LHC interview, prior to asking questions about IPV, each respondent was asked to report various life events that took place from the age at which she first started dating (or age 14, whichever was earlier) to the current age at interview, in the following domains: residence (timing of residential moves), schools attended, work history, births, welfare receipt, relationship history (the initials or first name of a partner, duration of the relationship, the level of sexual involvement, timing of cohabitation; marriage, separation, and/or divorce), and pregnancy outcomes that did not result in live births (miscarriage, abortion, stillbirth). In addition, each respondent was asked to identify memorable and/or significant events in her life other than those events in the preselected domains. Subsequently, each respondent was asked about the occurrence and timing of IPV (see below for details of measurement of IPV).

The interviewer recorded the timing of these events in a preprinted calendar-like form in plain view of the respondent, which allowed the respondent to use the information recorded on the calendar as an additional cue in recalling the occurrence and timing of IPV events.

\section{Structured Interview}

Following the LHC administration, the interviewer conducted a semistructured interview that covered current physical and mental health status (see Time-Fixed Variables below) and sociodemographic characteristics, as well as the respondent's perceptions about the effectiveness of the LHC method.

\section{Time-Varying Variables Constructed From the LHC Interview Data}

We obtained information about the occurrence of life events using 1 year as the time unit. Thus, for each year of the respondent's life from the time of first dating to the age of interview, we recorded whether particular life events (including IPV and welfare receipt) occurred or not, which resulted in a matrix-like data structure, with multiple observations for each respondent. To illustrate the data structure, while retaining confidentiality of respondents, data on a subset of variables from two fictional respondents are shown in Table I. The value of the "Current IPV" variable is 1 for those years in which the respondent experienced IPV (physical violence, sexual violence, and/or threats/harassment), and 0 in those years in which she did not. The number of different types of IPV experienced in each year is recorded in the sixth column of Table I. In addition, we constructed a variable indicating cumulative exposure to IPV in the past ("Cumulative Past IPV"). The value of this variable in year $t$ is calculated as the number of types of IPV experienced by the respondent in each year, summed over all years, from year of first relationship to year $t-1$. Similarly, the value of the time-varying variable "Current Welfare Receipt" is 1 in those years in which the respondent received welfare, and 0 in other years. The value of "Cumulative Past Welfare Receipt" in year $t$ represents the number of years in which the respondent received welfare, from year of first relationship to year $t-1$.

For instance, Respondent 1 was 25 at the time of interview and had a total of four partners, the first at age 14. She experienced IPV for the first time at age 17, while involved with her second partner, and reported two types of IPV in this year. She subsequently experienced IPV every year from the ages of 18 to 21, at the hands of a third partner, with the largest variety of types of IPV occurring at age 19. She had a fourth partner from the ages of 23-25 and at age 24 experienced a single type of IPV. By age 20, her cumulative past IPV count had reached 21 . She received welfare from age $20-22$ inclusive and again when 24 years old, i.e., for a total of 4 years.

Since, by definition, IPV can only occur within an intimate relationship, we analyzed only the years since the respondent had a first intimate relationship (dating years, hereinafter). The 40 women combined provided data on their welfare receipt, IPV, and other life events for a total of 722 personyears after the start of their first relationships. Based on these data, we created time-varying variables whose values change from year to year, as described below. 
Table I. Illustrative Example of Dataset Structure With Selected Variables of Interest Shown

\begin{tabular}{|c|c|c|c|c|c|c|c|c|}
\hline ID & $\begin{array}{c}\text { Year since first } \\
\text { relationship or } \\
\text { age } 14\end{array}$ & Age & Partner \# & Current IPV & $\begin{array}{c}\text { \# of IPV } \\
\text { types }\end{array}$ & $\begin{array}{l}\text { Cumulative } \\
\text { past IPV }\end{array}$ & $\begin{array}{l}\text { Current } \\
\text { welfare } \\
\text { receipt }\end{array}$ & $\begin{array}{l}\text { Cumulative past } \\
\text { welfare receipt }\end{array}$ \\
\hline \multirow[t]{12}{*}{1} & 1 & 14 & 1 & 0 & 0 & 0 & 0 & 0 \\
\hline & 2 & 15 & & 0 & 0 & 0 & 0 & 0 \\
\hline & 3 & 16 & 2 & 0 & 0 & 0 & 0 & 0 \\
\hline & 4 & 17 & 2 & 1 & 2 & 0 & 0 & 0 \\
\hline & 5 & 18 & 3 & 1 & 3 & 2 & 0 & 0 \\
\hline & 6 & 19 & 3 & 1 & 7 & 5 & 0 & 0 \\
\hline & 7 & 20 & 3 & 1 & 6 & 12 & 1 & 0 \\
\hline & 8 & 21 & 3 & 1 & 2 & 18 & 1 & 1 \\
\hline & 9 & 22 & & 0 & 0 & 20 & 1 & 2 \\
\hline & 10 & 23 & 4 & 0 & 0 & 20 & 0 & 3 \\
\hline & 11 & 24 & 4 & 1 & 1 & 20 & 1 & 3 \\
\hline & 12 & 25 & 4 & 0 & 0 & 21 & 0 & 4 \\
\hline \multirow[t]{11}{*}{2} & 1 & 13 & 1 & 1 & 1 & 0 & 0 & 0 \\
\hline & 2 & 14 & 2 & 0 & 0 & 1 & 0 & 0 \\
\hline & 3 & 15 & & 0 & 0 & 1 & 0 & 0 \\
\hline & 4 & 16 & 3 & 1 & 5 & 1 & 0 & 0 \\
\hline & 5 & 17 & 3 & 1 & 4 & 6 & 0 & 0 \\
\hline & 6 & 18 & & 0 & 0 & 10 & 0 & 0 \\
\hline & 7 & 19 & & 0 & 0 & 10 & 0 & 0 \\
\hline & 8 & 20 & 4 & 1 & 3 & 10 & 0 & 0 \\
\hline & 9 & 21 & & 0 & 0 & 13 & 1 & 0 \\
\hline & 10 & 22 & & 0 & 0 & 13 & 1 & 1 \\
\hline & 11 & 23 & & 0 & 0 & 13 & 1 & 2 \\
\hline
\end{tabular}

\section{Intimate Partner Violence (IPV)}

For each intimate relationship mentioned by the respondent in the first section of the LHC interview, the interviewer asked whether the respondent had experienced partners' physical and sexual violence and/or threat and harassment. Behaviorspecific questions assessed 12 types of physical violence, 2 types of sexual violence, and 8 types of threats and harassment. The types of IPV were drawn from previous studies in the general U.S. population (Marshall, 1992; Straus, 1990), augmented with items pertinent to low-income women's lives (Tolman \& Rosen, 2001). For each type of IPV reported, the interviewer probed about the age (or calendar year) at which the respondent experienced that type of IPV for the first time, and whether it happened in any of the subsequent years.

As noted above, we constructed a time-varying variable ("Current IPV") that indicated whether the respondent had experienced any IPV (physical violence, sexual violence, and/or threats/harassment) in each year. This was used as the dependent variable in a GEE analysis that examined whether previous welfare receipt was associated with subsequent experience of IPV (see below). In addition, we constructed a variable indicating cumulative exposure to IPV in the past ("Cumulative Past IPV"). The value of this time-varying variable in year $t$ is calculated as the number of IPV types the respondent experienced in each year, summed over all years, from year of first relationship to year $t-1$. This variable was used as an independent variable in GEE analyses when assessing the extent to which cumulative exposure to IPV was associated with respondents' health status.

\section{Welfare Receipt}

The respondent was asked whether she had received any form of public assistance or benefits, and, if so, the age at which she first received them and for how long she received them. She was also asked about the timing and duration of subsequent welfare receipt. Similar to the IPV variables, we constructed two types of time-varying variables: whether the respondent received welfare benefits in a given year ("Current Welfare Receipt"), and the total number of years in which the respondent had received welfare benefits through the previous year ("Cumulative Past Welfare Receipt"). These two variables were used in GEE analyses as described below. 


\section{Cumulative Employment Experiences}

The respondent was asked what jobs she had held and how long she had held each job. This information yielded binary data on whether or not the respondent was working for each year of her life up to the interview. ${ }^{4}$ Based on this information, we created a time-varying variable that indicated the cumulative number of years in which the respondent worked up to the previous year.

\section{Cumulative Number of Children}

The respondent was asked in what year each of her children was born. Based on this information, we created a time-varying variable that indicated the cumulative number of children that the respondent had given birth to up to the previous year.

\section{Current Relationship Status}

We created a variable that indicated whether the respondent was married, cohabiting with a partner, partnered but not cohabiting with a partner, or not partnered in a given year.

\section{Time-Fixed Variables}

\section{Self-Rated Health Status}

The respondent was asked to rate her health status at interview on a 5-point Likert scale, ranging from $1=$ excellent to $5=$ poor. For multivariate analyses, we created a 4-level variable by combining the values 4 and 5 because of small numbers of respondents in these categories.

\section{Interference With Work Due to Health Status}

Using an item from the SF-36 (Ware \& Sherbourne, 1992), the respondent was asked to rate the degree to which "physical health and emotional problems, such as feeling depressed or anxious, interfered with her normal work including both work outside the home and housework" during the past 4 weeks. The response was obtained on a 5-point scale, ranging from $1=$ not at all to $5=$ extremely.

\footnotetext{
${ }^{4}$ Employment was coded as 1 if the respondent worked for a period of 2 months or more during that year.
}

For multivariate analyses, we created a 3-level variable by combining values 3,4 , and 5 because of few respondents in these categories.

\section{Posttraumatic Stress Disorder (PTSD)}

Using the PTSD module of the Composite International Diagnostic Interview (CIDI) (World Health Organization, 1997), we obtained information from the respondent about the lifetime occurrence of reexperiencing, avoidance, and numbing, and arousal symptoms, as well as the criterion A (exposure to a traumatic event and intense fear, helplessness, or horror). Based on this information, we created a past 12-month PTSD diagnosis using the DSM-IVR criteria.

Age

We trichotomized the respondents' age at interview into $18-29,30-39$, and 40 and above.

\section{Education}

Respondents' education was dichotomized based on whether or not they had obtained a high school degree or GED.

\section{Relationship Status at Interview}

We created a binary variable that indicated whether or not the respondent was married or cohabiting with a partner at interview or in the year preceding the year of interview.

\section{Statistical Analysis}

To examine whether previous receipt of welfare was associated with a subsequent increase in experience of IPV, we used a type of longitudinal data analysis called Generalized Estimating Equations (GEE). For each person in the data set, the GEE model can be represented as a multivariate regression equation:

$$
\begin{aligned}
\log \text { odds of } \mathrm{IPV}_{t}= & \beta_{0}+\beta_{1} \mathrm{cIPV}_{t-1}+\beta_{2} \mathrm{cW}_{t-1} \\
& +\beta_{3} \mathrm{U}_{t} .
\end{aligned}
$$

Here $t$ represents time since first intimate relationship in years and runs from 1 to $K$. Here $K$ represents the number of years from the first intimate 
relationship to the time of interview, and in our data ranged from 1 to 37 . The response variable $\mathrm{IPV}_{t}$ indicates whether or not the respondent experienced IPV in year $t$, the variable IPV $_{t-1}$ represents cumulative IPV up to year $t-1, \mathrm{cW}_{t-1}$ represents cumulative welfare receipt up to year $t-1$, and $\mathrm{U}_{t}$ represents other time-varying covariates that are theoretically and/or empirically linked to either IPV or welfare receipt, such as number of children, prior work experience, and relationship status in year $t$.

To examine the relationship between IPV and subsequent welfare receipt, we fit a similar model with the response variable $y_{t}$ representing whether or not the respondent received welfare in year $t$.

We then assessed whether cumulative exposure to IPV and cumulative welfare receipt were associated with the respondent's physical and mental health as recorded at time of interview. For dichotomous outcome variables, such as the PTSD diagnosis, we used logistic regression, and for ordinal outcome variables, such as self-rated health status and interference with work due to health status, we used an ordered logit (also known as a cumulative logit) model. These analyses were conducted controlling for risk factors known to be associated with health status, such as age, education, relationship status, and number of children (Avis, Assmann, Kravitz, Ganz, \& Ory, 2004; Keyes, 2004; Weng, Bastian, Taylor, Moser, \& Ostbye, 2004; Yen \& Moss, 1999). For these analyses, because the number of years in which the respondent had experienced IPV prior to the interview was a function of her age at interview, we created a variable indicating the proportion of dating years in which the respondent experienced IPV. Similarly, we created a variable indicating the proportion of dating years in which the respondent received welfare benefits. The values of these variables were standardized ( $z$-scores) and used in the regression models predicting the health status at interview.

\section{RESULTS}

\section{Respondents' Characteristics and Experiences With Welfare and IPV}

At the time of interview, the mean age of the respondents was 32.3 (range 18-50), and two-thirds $(67.5 \%)$ had received their high school diploma or GED (see Table II). On average, the women had three children, and had had their first child at age

Table II. Respondents' Characteristics and Health Status at Interview $(N=40)$

\begin{tabular}{lrrr}
\hline & $N$ & $\%$ & Mean $(S D)$ \\
\hline Age & & & $32.30(7.57)$ \\
$18-29$ & 14 & 35.0 & \\
$30-39$ & 7 & 17.5 & \\
$40+$ & 27 & 67.5 & $11.65(1.42)$ \\
Years of education & & & $3.23(1.59)$ \\
Obtained HS diploma or GED & & & $18.15(1.99)$ \\
Number of children & & & \\
Age at birth of first child & 23 & 57.5 & \\
Relationship status & 8 & 20.0 & \\
$\quad$ Partnered but not cohabitating & 5 & 12.5 & \\
Cohabitating, not married & 4 & 10.0 & \\
Married & 31 & 77.5 & \\
$\quad$ Not partnered & 35 & 87.5 & \\
Working during the year of interview & 37 & 92.5 & \\
Receiving welfare at interview & 7 & 17.5 & \\
Experienced IPV in the past & & & \\
Experienced IPV in the year of interview & 11 & 27.5 & \\
Self-rated health & 11 & 27.5 & \\
$\quad$ Excellent & 12 & 30.0 & \\
Very good & 6 & 15.0 & \\
$\quad$ Good & & & \\
Fair or poor & 14 & 35.0 & \\
Health interfered with work & 11 & 27.5 & \\
$\quad$ Not at all & 15 & 37.5 & \\
A little bit & 10 & 25.0 & \\
$\quad$ Moderately, quite a bit, or extremely & & & \\
Met diagnostic criteria for PTSD within the past 12 months & & \\
\hline
\end{tabular}


Table III. Years of Significant Life Events as a Percentage of 722 Total Person-Years

\begin{tabular}{lcc}
\hline & $\begin{array}{c}\text { Number of } \\
\text { person-years }\end{array}$ & $\begin{array}{c}\text { Percentage } \\
\text { of total } \\
\text { person-years }\end{array}$ \\
\hline Relationship status & & \\
Partnered & 323 & 44.74 \\
Cohabitating & 265 & 36.70 \\
Married and cohabitating & 61 & 8.45 \\
Not partnered & 73 & 10.11 \\
In school & 246 & 34.07 \\
Working & 422 & 58.45 \\
Receipt of welfare & 483 & 66.99 \\
Physical, sexual, or emotional & 279 & 38.64 \\
$\quad$ violence & & \\
\hline
\end{tabular}

18. Most of the respondents had an intimate partner in the year of interview and were working. Although sampled from the list of welfare recipients, not all the respondents received welfare benefits in the year of the interview. The majority $(92.5 \%)$ reported having experienced some type of IPV $(87.5 \%$ physical violence, $52.5 \%$ sexual violence, and $70 \%$ threats and harassment) in the past, and $17.5 \%$ in the year of interview.

While most of the respondents $(85 \%)$ rated their overall health status as "good," "very good," or "excellent," $65 \%$ reported that health problems had interfered with their work at least "a little bit," with $37.5 \%$ reporting that health problems had interfered with their ability to work "moderately," "quite a bit," or "extremely." At the time of interview, $25 \%$ of the sample met the diagnostic criteria of PTSD.

As shown in Table III, the respondents were in intimate relationships in 649 person-years out of the 722 person-years since the first intimate partner ( $90 \%$ ); however, they were married in only $8 \%$ of the person-years. The respondents worked at least some of the time in over half of the person-years $(58 \%)$, and received some type of welfare benefits in twothirds of the person-years $(66.9 \%)$. In over one-third of the person-years $(38.6 \%)$, the respondents experienced partners' physical, sexual, and/or emotional violence.

\section{Bivariate Cross-Sectional Analyses}

Using cross-tabulation, we first examined whether the respondents' experiences of IPV and welfare receipt were associated. Chi-square tests of independence demonstrated a significant relationship between the receipt of welfare and the experience of IPV in the same year: respondents experienced IPV in $43.1 \%$ of the person-years in which they were on welfare, compared to $30 \%$ of the personyears in which they were not on welfare $\left(\chi^{2}=12.03\right.$, $p=.0005)$. Since this type of cross-sectional analysis does not consider the temporal sequence of events, in the next section we use a longitudinal GEE model to assess changes in the probability of welfare receipt and IPV over the women's lifecourses.

\section{Longitudinal Analyses Predicting IPV Experience and Welfare Receipt}

As shown in Table IV, controlling for the number of children, prior work experience, and relationship status, cumulative past welfare receipt was not significantly associated with current welfare receipt in a given year $(\beta=-0.11, p=.32)$ or current IPV $(\beta=0.03, p=.55)$. In contrast, cumulative past IPV exposure was significantly positively associated with current welfare receipt $(\beta=0.04, p=.04)$.

Table IV. Results of GEE Analyses Predicting the log Odds of Receiving Welfare and the log Odds of Experiencing IPV

\begin{tabular}{|c|c|c|c|c|c|c|}
\hline & \multicolumn{3}{|c|}{ Predicting current welfare receipt } & \multicolumn{3}{|c|}{ Predicting current IPV } \\
\hline & $\beta$ & $S E$ & $p$ & $\beta$ & $S E$ & $p$ \\
\hline Cumulative past welfare receipt & -0.11 & 0.08 & 0.32 & 0.03 & 0.04 & 0.55 \\
\hline Cumulative past IPV & 0.04 & 0.01 & 0.04 & 0.01 & 0.01 & 0.16 \\
\hline Number of children & 0.35 & 0.17 & 0.02 & 0.05 & 0.09 & 0.62 \\
\hline Cumulative years of employment & 0.15 & 0.08 & 0.06 & -0.07 & 0.04 & 0.06 \\
\hline \multicolumn{7}{|l|}{ Current relationship status } \\
\hline Partnered & -0.57 & 0.27 & & 1.15 & 0.46 & \\
\hline Cohabitating & -0.36 & 0.30 & & 2.30 & 0.60 & \\
\hline Married & -0.80 & 0.34 & & 2.71 & 0.66 & \\
\hline Not partnered & Reference & & 0.05 & Reference & & 0.002 \\
\hline
\end{tabular}


Table V. Results of Regression Models Predicting Health Status at Interview

\begin{tabular}{|c|c|c|c|c|c|c|c|c|c|}
\hline & \multicolumn{6}{|c|}{ Cumulative logit models } & \multirow{2}{*}{\multicolumn{3}{|c|}{ Logistic regression model }} \\
\hline & \multirow{2}{*}{\multicolumn{3}{|c|}{$\begin{array}{l}\text { Self-rated health status (higher } \\
\text { score = poorer health) }\end{array}$}} & \multirow{2}{*}{\multicolumn{3}{|c|}{$\begin{array}{l}\text { Interference with work due to } \\
\text { health status (higher score }= \\
\text { more work interference }\end{array}$}} & & & \\
\hline & & & & & & & \multicolumn{3}{|c|}{ Past 12-month PTSD } \\
\hline & $\beta$ & $S E$ & $p$ & $\beta$ & $S E$ & $p$ & $\beta$ & $S E$ & $p$ \\
\hline $\begin{array}{l}\text { Proportion of dating years that } \\
\text { respondent experienced IPV } \\
\text { (standardized) }\end{array}$ & 3.25 & 1.47 & 0.02 & 3.66 & 1.58 & 0.01 & 3.44 & 1.98 & 0.06 \\
\hline Received welfare (standardized) & 1.45 & 1.62 & 0.37 & 1.89 & 1.56 & 0.22 & 3.78 & 2.75 & 0.12 \\
\hline \multicolumn{10}{|l|}{ Age at interview } \\
\hline $18-29$ & -1.87 & 1.03 & & -0.87 & 1.02 & & -0.99 & 1.38 & \\
\hline $30-39$ & -2.35 & 0.96 & & -0.94 & 0.97 & & -0.53 & 1.25 & \\
\hline 40 and older & Reference & & 0.03 & Reference & & 0.59 & Reference & & 0.77 \\
\hline $\begin{array}{l}\text { Cohabitating or married in the } \\
\text { year of interview }\end{array}$ & 0.76 & 0.69 & 0.26 & 0.37 & 0.76 & 0.63 & -0.79 & 1.11 & 0.46 \\
\hline Completed high school or GED & 0.19 & 0.73 & 0.80 & 2.32 & 0.87 & 0.004 & -1.32 & 1.01 & 0.19 \\
\hline Number of children & 0.05 & 0.21 & 0.80 & 0.07 & 0.23 & 0.75 & -0.23 & 0.32 & 0.46 \\
\hline
\end{tabular}

\section{Regression Analyses Predicting Current Health Status}

We then examined whether the probability of worse self-rated health at interview, interference with work due to physical and mental health problems, and a PTSD diagnosis in the past 12 months, were associated with cumulative IPV or welfare receipt. These analyses were conducted controlling for factors associated with health and mental health status, such as age, education, number of children, and relationship status at interview.

As shown in Table $\mathrm{V}$, the proportion of dating years in which the respondent experienced IPV was associated with both worse self-rated health status $(\beta=3.25, p=.02)$ and more interference with work due to physical and mental health problems $(\beta=$ $3.66, p=.01)$, controlling for all other covariates in the model. However, the proportion of dating years in which the respondent received welfare benefits had no effect on self-rated health status or health problems interfering with work. The results of a logistic regression showed that, controlling for age, education, number of children, and relationship status, the proportion of dating years in which the respondent experienced IPV was positively associated with the past-12-month PTSD diagnosis $(\beta=3.44, p=$ $.06)$. An increase of one standard deviation (0.25) in the proportion of dating years with IPV increased the odds of past-12-month PTSD by $\exp (3.44)=31.2$, adjusting for all other covariates in the model. The proportion of dating years in which the respondent re- ceived welfare benefits was not associated with past year PTSD $(\beta=3.78, p=.12)$.

\section{DISCUSSION}

Our findings point to the importance of temporal sequence in understanding women's experiences of IPV in the context of interacting factors at different levels of the ecology. Our analyses found that cumulative past IPV was significantly associated with current welfare receipt in a given year, but that previous welfare receipt did not increase the odds of subsequently experiencing IPV. This finding extends previous research that has documented a higher prevalence of IPV among women on welfare than in the general population of women by elucidating the importance of the temporal sequence of these significant life events. Additionally, the notable finding that cumulative welfare receipt was not associated with current welfare receipt in a given year suggests that, contrary to many mainstream depictions of welfare recipients in the media and elsewhere, women who receive welfare at one point in time are no more likely to remain on welfare than women who do not have a history of welfare receipt. In addition, this finding is consistent with the hypothesis that IPV is a cause, rather than a result, of poverty and suggests that a deviant "culture of poverty" sustained by the welfare system is a fallacy.

This study found lifetime rates of IPV that were higher than those found in previous studies with 
similar populations. The proportion of women who had experienced IPV some time in the past $(92.5 \%)$ was higher than the $73.0 \%$ found by Marshall and Honeycutt (1999, as reported by Tolman \& Raphael) among women on public assistance in a Southern metropolitan community. Lifetime reports of physical IPV in this sample $(87.5 \%)$ were also higher than those found in similar populations [29\% (Lloyd \& Taluc, 1999) to $74 \%$ (Barusch et al., 1999)]. The wide variability in reported lifetime rates of IPV has been interpreted as resulting from variable definitions of IPV from study to study, as well as to contextual differences in spatiotemporal locations (given the variability in state welfare regulations over time; Tolman \& Raphael, 2000). The present study expands these interpretations to suggest that data collection methods are also important in eliciting complete information about a woman's history of IPV, particularly IPV that has occurred over her lifecourse.

This study of low-income African American women found that respondents' self-reported health status $-15 \%$ rating their health as fair or poor and $25 \%$ meeting a PTSD diagnostic criteria-was worse than that of the general female population in the United States [9.2\% (Schiller \& Bernadel, 2004) and $10.4 \%$ (Kessler et al., 1995), respectively]. In addition, greater cumulative IPV exposure was associated with worse self-rated health, which has been shown to be a good indicator of subsequent morbidity and mortality (Fryers et al., 2003; McDonough et al., 1997; Ren et al., 1999; Sorlie et al., 1995). Greater cumulative IPV exposure was also associated with the likelihood that self-reported symptoms met the diagnostic criteria for PTSD, as well as the likelihood that the respondents' physical health and emotional problems interfered with their work. These results point to the importance of taking into account the physical and mental health consequences of IPV among welfare recipients in health and mental health settings. Additionally, work requirements imposed on welfare recipients must consider the increased rate of compromised health and mental health in welfare recipients. Interventions must address not only individual women's health and mental health needs, but also the mezzo and macro levels of human ecology (discussed below).

The results of this study should be assessed in light of the following considerations and limitations. First, we collected data on IPV from only one source: the woman involved in the relationship. Although the use of self-report data from a single source is subject to self-report bias, evidence suggests that women's reports of IPV are affected less by social desirability than are self-reports of male partners (Arias \& Beach, 1987; Dutton \& Hemphill, 1992). More importantly, when obtaining lifetime reports of IPV, it is not feasible to interview all of the partners that a respondent has had throughout her life. Because IPV is often committed in privacy, verifying respondents' experiences of IPV is difficult; other data sources, such as hospital and police records are usually incomplete as they are subject to the victims' and/or perpetrators' willingness to report the incidents. Considering these challenges, the use of women's self-report appears to be the best viable option for obtaining information on women's lifetime experiences of IPV.

Second, the respondents were racially homogenous. Although IPV cuts across racial and ethnic boundaries, and all women, regardless of race or ethnicity, need financial assistance in times of economic hardships, there may be differences in how women experience the welfare system, cope with IPV, and manifest health effects of IPV based on their race and/or ethnicity (Campbell, Masaki, \& Torres, 1997; Lee, Thompson, \& Mechanic, 2002; Thompson et al., 2000; Yoshihama, 2002). Thus, while the racially homogeneous sample limits our ability to generalize the results to women of other racial backgrounds, it avoids the problem of aggregating the data from women of different races whose experiences may differ considerably. Specifically, our results may be generalized to populations of low-income African American women aged 18-50 living in urban environments. Further research is needed to examine the relationship among IPV, welfare receipt, and mental health issues in other racial and ethnic groups of women.

Our study was conducted in early 2000, three-and-one-half years after the enactment of PRWORA. Although the particular state in which this study was conducted had not yet imposed lifetime limits on welfare receipt at the time of interview, it is possible that some of the respondents in this study may have been propelled to stop receiving welfare benefits in order to avoid reaching the lifetime limits, should they be imposed at a later date. Welfare eligibility workers might have been more actively prompting women to find other sources of income compared to the time period before PRWORA. Nevertheless, the effect of the policy change on the results of our study is probably limited because we estimated the probability of receiving welfare or experiencing IPV for each year of 
a respondent's adult life; thus, changes in behavior prompted in the years proximate to the interview, if present, had little effect on the overall results of the analysis.

Lastly, the methodological implications of this study deserve mention. We used a retrospective rather than prospective design: data for each year of a respondent's life were collected retrospectively at one interview. It is possible that some respondents, especially older respondents whose recall period was longer, were not able to remember all the details about their life experiences. To address this potential memory problem, we used the LHC method. Accumulating evidence suggests that, compared to widely-used structured interview methods, the LHC method enhances the quality of self-report, especially for older respondents (Belli et al., 2001; Yoshihama et al., 2005).

A distinct strength of this study is the use of longitudinal analyses that allowed for an examination of the relationship between IPV and welfare receipt taking into account their relative temporal sequence. Not only was our study able to capture variations among 40 women, but also variations over time within a single individual with respect to experiences of IPV and welfare receipt, as well as many other life conditions such as employment status, pregnancies, and geographic mobility. The ability to systematically collect data on these temporally shifting variables at different levels of the ecology is an important contribution of the LHC method to the study of welfare receipt, IPV, and health status. While a prospective longitudinal design can minimize recall bias, longitudinal studies are costly, require long study periods, and are likely to suffer from sample attrition. While we wait for long-term prospective studies currently underway or proposed, this investigation can immediately address the high prevalence of IPV and its serious health and social costs. Retrospective data collection using the LHC, we believe, is a viable option that is more cost-effective than longitudinal studies and can provide rich data to help understand the temporally shifting effects of IPV and welfare receipt on women's lives.

Our results suggest that understanding welfare receipt, IPV, and health status within an ecological framework may be useful for developing interventions at specific levels of the ecology. For example, our findings support the literature that implicates IPV as a significant barrier to long-term stable employment for low-income women (Browne et al., 1999; Honeycutt et al., 2001), and suggest a need for mezzo- and macro-level interventions, such as coalition building among organizations aimed at ending poverty and those aimed at ending IPV, community-level IPV prevention/intervention programs, and federal policies that make an explicit connection between elimination of IPV and the promotion of women's economic well-being. Enhanced women's economic well-being, in turn, will reduce the numbers of women on welfare, which is a major policy agenda of previous and current federal and local administrations.

We concur with previous researchers that PRWORA should remain committed to implementing programs to keep women safe from abuse as a first priority (Hetling-Wernj \& Born, 2003; Lein et al., 2001; Raphael \& Haennicke, 1999); however, the underutilization of the FVO and similar measures (Hetling-Wernj \& Born, 2003; Lein et al., 2001; Moore \& Selkowe, 1999; Raphael \& Haennicke, 1999) may be an indication that expecting individual women to take action is insufficient, and additional mezzo- and macro-level interventions are necessary. Our findings suggest that compromised physical and mental health may impede women's abilities to apply for exemptions, follow through with referrals, or fulfill other program requirements (such as filling out forms and attending support group meetings); women may require physical and mental health services before they can comply with the program requirements. Participation in physical and mental health services, as well as other activities designed to address barriers to employment, should be counted as satisfying the work requirements, as suggested by Goldberg (2002).

We urge policymakers and state and local administrators to identify the barriers that women may encounter as they navigate the welfare system, and to make changes that will increase effectiveness of IPV intervention within the system, such as increasing numbers of domestic violence advocates in welfare agencies, as has been suggested by HetlingWernj and Born (2003) and Raphael and Haennicke (1999). Although such services would require additional resources, these additional resources probably will cost the system less in the long-run than not addressing the physical and mental consequences of IPV, which would result in many women remaining on welfare. Further, although the FVO and similar programs are critically important in the lives of lowincome women who have experienced IPV, they are only applicable after women experience IPV and suffer economic hardship. In light of the finding that 
cumulative IPV was associated with subsequent welfare receipt, stronger policies and programs aimed at preventing IPV are necessary.

\section{REFERENCES}

Arias, I., \& Beach, S. (1987). Validity of self-reports of marital violence. Journal of Family Violence, 2, 139-149.

Astin, M. C., Lawrence, K. J., \& Foy, D. W. (1993). Posttraumatic stress disorder among battered women: Risk and resiliency factors. Violence and Victims, 8, 17-28.

Avis, N. E., Assmann, S. F., Kravitz, H. M., Ganz, P. A., \& Ory, M. (2004). Quality of life in diverse groups of midlife women: Assessing the influence of menopause, health status and psychosocial and demographic factors. Quality of Life Research, 13, 933-946.

Barusch, A., Taylor, M. J., \& Derr, M. (1999). Understanding families with multiple barriers to self-sufficiency. Salt Lake City: University of Utah, Research Institute.

Bassuk, E. L., Weinreb, L. F., Buckner, J. C., Browne, A., Salomon, A., \& Bassuk, S. S. (1996). The characteristics and needs of sheltered homeless and low-income housed mothers. JAMA, 276, 640-646.

Belli, R. F. (1998). The structure of autobiographical memory and event history calendar: Potential improvements in the quality of retrospective reports in survey. Memory, 6, 383-406.

Belli, R. F., Shay, W. L., \& Stafford, F. P. (2001). Event history calendars and question list surveys: A direct comparison of interviewing methods. Public Opinion Quarterly, 65, 45-74.

Breslau, N., \& Davis, G. C. (1992). Posttraumatic stress disorder in an urban population of young adults: Risk factors for chronicity. American Journal of Psychiatry, 149, 671-675.

Breslau, N., Davis, G. C., Peterson, E. L., \& Schultz, L. (1997). Psychiatric sequelae of posttraumatic stress disorder in women. Archives of General Psychiatry, 54, 81-87.

Bronfenbrenner, U. (1979). The ecology of human development: Experiments by nature and design. Cambridge, MA: Harvard University Press.

Browne, A., Salomon, A., \& Bassuk, S. S. (1999). The impact of recent partner violence on poor women's capacity to maintain work. Violence Against Women, 5, 393-426.

Brownridge, D., \& Halli, S. (2002). Double Jeopardy?: Violence against immigrant women in Canada. Violence and Victims, 11, 455-471.

Brush, L. D. (2000). Battering, traumatic stress, and welfare-towork transition. Violence Against Women, 6, 1039-1065.

Burgess, A. W., Baker, T., Greening, D., Hartmann, C. R., Burgess, A. G., Douglass, J. E., et al. (1997). Stalking behaviors within domestic violence. Journal of Family Violence, 12, 389-403.

Campbell, D. W., Masaki, B., \& Torres, S. (1997). "Water on rock": Changing domestic violence perceptions in the African American, Asian American, and Latino communities. In E. Klein, J. Campbell, E. Soler, \& M. Ghez (Eds.), Ending domestic violence: Changing public perceptions/Halting the epidemic (pp. 64-87). Thousand Oaks, CA: Sage.

Campbell, J., Jones, A. S., Dienemann, J., Kub, J., Schollenberger, J., O'Campo, P., et al. (2002). Intimate partner violence and physical health consequences. Archives of Internal Medicine, $162,1157-1163$.

Campbell, J. C. (2002). Health consequences of intimate partner violence. Lancet, 359, 1331-1336.

Campbell, J. C., \& Soeken, K. L. (1999). Forced sex and intimate partner violence: Effects on women's risk and women's health. Violence Against Women, 5, 1017-1035.

Cascardi, M., O'Leary, K. D., \& Schlee, K. A. (1999). Cooccurrence and correlates of posttraumatic stress disorder and major depression in physically abused women. Journal of Family Violence, 14, 227-249.

Coker, A. L., Smith, P. H., McKeown, R. E., \& King, M. J. (2000). Frequency and correlates of intimate partner violence by type: Physical, sexual, and psychological battering. American Journal of Public Health, 90, 553-559.

Cole, P. R. (2001). Impoverished women in violent partnerships: Designing services to fit their reality. Violence Against Women, 7, 222-233.

Collins, K. S., Schoen, C., Joseph, S., Duchon, L., Simantov, E., \& Yellowitz, M. (1999). Health concerns across a woman's lifespan: The commonwealth fund 1998 survey of women's health. New York: Commonwealth Fund.

Colten, M. E., Cosenza, C., \& Allard, M. A. (1996). Domestic violence among Massachusetts AFDC recipients: Preliminary results. Boston: University of Massachusetts Center for Survey Research.

Corcoran, M., Danziger, S., \& Tolman, R. (2004). Long term employment of African American and White welfare recipients and the role of persistent health and mental health problems. Women and Health, 39, 21-40.

Danziger, S., Corcoran, M., Danziger, S., Heflin, C., Kalil, A., Levine, J., et al. (2002). Barriers to the employment of welfare recipients. In R. Cherry \& W. Rodgers (Eds.), Prosperity for all? The economic boom and African Americans (pp. 245-278). New York: Sage.

Dutton, D. G., \& Hemphill, K. J. (1992). Patterns of socially desirable responding among perpetrators and victims of wife assault. Violence and Victims, 7, 29-39.

Freedman, D., Thornton, A., Camburn, D., Alwin, D., \& YoungDeMarco, L. (1988). The life history calendar: A technique for collecting retrospective data. In C. C. Clogg (Ed.), Sociological methodology (pp. 37-68). San Francisco: Jossey-Bass.

Fryers, T., Melzer, D., \& Jenkins, R. (2003). Social inequalities and the common mental disorders: A systematic review of the evidence. Social Psychiatry and Psychiatric Epidemiology, 38, 229237.

Gelles, R. J., \& Harrop, J. W. (1989). Violence, battering, and psychological distress among women. Journal of Interpersonal $\mathrm{V} i$ olence, 4, 400-420.

Geronimus, A. T. (1992). The weathering hypothesis and the health of African American women and infants: Evidence and speculations. Ethnicity and Disease, 2, 207-221.

Goldberg, H. (2002). Improving TANF program outcomes for families with barriers to employment. Washington, DC: Center on Budget and Policy Priorities.

Golding, J. M. (1999). Intimate partner violence as a risk factor for mental disorders: A meta- analysis. Journal of Family Violence, 14, 99-132.

Green, L. W., Richard, L., \& Potvin, L. (1996). Ecological foundations of health promotion. American Journal of Health Promotion, 10, 270-281.

Heise, L. L. (1998). Violence against women: An integrated, ecological framework. Violence Against Women, 4, 262-290.

Hetling-Wernj, A., \& Born, C. (2003). Domestic violence and welfare receipt in Maryland: Linking individual outcomes to implementation and jurisdictional differences. Baltimore: Family Welfare Research and Training Group.

Honeycutt, T. C., Marshall, L. L., \& Weston, R. (2001). Toward ethnically specific models of employment, public assistance, and victimization. Violence Against Women, 7, 126-140.

Horwitz, S., \& Kerker, B. D. (2001). Impediments to employment under welfare reform: The importance of physical health and psychosocial characteristics. Women and Health, 32, 101-117.

Kemp, A., Rawlings, E. I., \& Green, B. L. (1991). Post-traumatic stress disorder (PTSD) in battered women: A shelter sample. Journal of Traumatic Stress, 4, 137-148.

Kessler, R. C., McGonagle, K. A., Zhao, S. Y., Nelson, C. B., Hughes, M., Eshleman, S., et al. (1994). Lifetime and 12-month 
prevalence of DSM-III-R psychiatric disorders in the United States: Results from the National Comorbidity Study. Archives of General Psychiatry, 51, 8-19.

Kessler, R. C., Sonnega, A., Bromet, E., Hughes, M., \& Nelson, C. B. (1995). Posttraumatic stress disorder in the National Comorbidity Survey. Archives of General Psychiatry, 52, 10481060.

Keyes, C. L. M. (2004). The nexus of cardiovascular disease and depression revisited: The complete mental health perspective and the moderating role of age and gender. Aging and Mental Health, 8, 266-274.

Klein, E., Campbell, J., Soler, E., \& Ghez, M. (1997). Ending domestic violence: Changing public perceptions/halting the epidemic. Thousand Oaks, CA: Sage.

Kneipp, S. M. (2000). The health of women in transition from welfare to employment. Western Journal of Nursing Research, 22, 656-682.

Krieger, N., Rowley, D. L., Herman, A. A., Avery, B., \& Phillips, M. T. (1993). Racism, sexism, and social class: Implications for studies of health, disease, and well-being. American Journal of Preventive Medicine, 9, 82-122.

Lee, R. K., Thompson, V. L. S., \& Mechanic, M. B. (2002). Intimate partner violence and women of color: A call for innovations. American Journal of Public Health, 92, 530-534.

Lein, L., Jacquet, S. E., Lewis, C. M., Cole, P. R., \& Williams, B. B. (2001). With the best of intentions: Family violence option and abused women's needs. Violence Against Women, 7, 193210.

Lennon, M. C., Blome, J., \& English, K. (2002). Depression among women on welfare: A review of the literature. Journal of the American Medical Women's Association, 57, 27-32.

Lloyd, S., \& Taluc, N. (1999). The effects of male violence on female employment. Violence Against Women, 5, 370-392.

Marshall, L. L. (1992). The severity of violence against women scales. Journal of Family Violence, 7, 189-203.

Marshall, L. L., \& Honeycutt, T. C. (1999). Women, domestic abuse and public assistance. Unpublished manuscript, University of North Texas.

McCauley, J., Kern, D. E., Kolodner, K., Dill, L., Schroeder, A. F., Dechant, H. K., et al. (1995). The battering syndrome: Prevalence and clinical characteristics of domestic violence in primary-care internal-medicine practices. Annals of Internal Medicine, 123, 737-746.

McDonough, P., Duncan, G. J., Williams, D., \& House, J. (1997). Income dynamics and adult mortality in the United States, 1972 through 1989. American Journal of Public Health, 87, 14761483.

McPherson, J. M., Popielarz, P. A., \& Drobnic, S. (1992). Social network and organizational dynamics. American Sociological Review, 57, 153-170.

Moore, T., \& Selkowe, V. (1999). Domestic violence in transition from welfare to work: Barriers to self-sufficiency and the W-2 Response. Milwaukee, WI: The Institute for Wisconsin's Future.

Polit, D., London, A., \& Martinez, J. (2001). The health of poor urban women: Findings from the Project on Devolution and Urban Change. New York: Manpower Demonstration Research Corporation.

Raphael, J. (2002). Keeping battered women safe during welfare reform: New challenges. Journal of American Medical Women's Association, 57, 32-35.

Raphael, J., \& Haennicke, S. (1999). Keeping battered women safe through the welfare-to-work journey: How are we doing? A report on the implementation of policies for battered women in state Temporary Assistance for Needy Families (TANF) programs. Washington, DC: Taylor Institute.

Regier, D. A., Narrow, W. E., Rae, D. S., Manderscheid, R. W., Locke, B. Z., \& Goodwin, F. K. (1993). The de facto United States mental and addictive disorders service system. Archives of General Psychiatry, 50, 85-94.
Ren, X. S., Benjamin, C. A., \& Williams, D. R. (1999). Racial/ethnic disparities in health: The interplay between discrimination and socioeconomic status. Ethnicity and Disease, 9, 151-165.

Rennison, C. M., \& Welchans, S. (2000). Intimate partner violence, Bureau of justice statistics special report (NCJ 178247). Washington, DC: U.S. Department of Justice.

Resnick, H. S., Kilpatrick, D. G., Dansky, B. S., Saunders, B. E., \& Best, C. L. (1993). Prevalence of civilian trauma and posttraumatic stress disorder in a representative national sample of women. Journal of Consulting and Clinical Psychology, 61, 984 991.

Riger, S., \& Krieglstein, M. (2000). The impact of welfare reform on men's violence against women. American Journal of Community Psychology, 28, 631-647.

Robbins, L. N., Locke, B. Z., \& Regier, D. A. (1991). An overview of psychiatric disorders in America. In L. N. Robbins \& D. A. Regier (Eds.), Psychiatric disorders in America: The epidemiologic catchment area study (pp. 328-366). New York: Free.

Saunders, D. G. (1994). Posttraumatic stress symptoms profile of battered women: A comparison of survivors in two settings. $\mathrm{Vi}$ olence and Victims, 9, 31-44.

Schiller, J. S., \& Bernadel, L. (2004). Summary health statistics for the U.S. population: National Health Interview Survey, 2002. Hyattsville, MD: U.S. Department of Health and Human Services Centers for Disease Control and Prevention National Center for Health Statistics and Prevention.

Sherman, L. W., Schmidt, J. D., Rogan, D. P., Gartin, P. R., Cohn, E. G., Collins, D. J., et al. (1991). From initial deterrence to long-term escalation: Short-custody arrest for poverty ghetto domestic violence. Criminology, 29, 821-850.

Sorenson, S. B., Upchurch, D. M., \& Shen, H. (1996). Violence and injury in marital arguments: Risk patterns and gender differences. American Journal of Public Health, 86, 35-40.

Sorlie, P. D., Backlund, E., \& Keller, J. B. (1995). U.S. mortality by economic, demographic, and social characteristics: The National Longitudinal Mortality Study. American Journal of Public Health, 85, 949-956.

Stokols, D. (1996). Translating social ecological theory into guidelines for community health promotion. American Journal of Health Promotion, 10, 282-298.

Straus, M. A. (1990). Measuring intrafamily conflict and violence: The Conflict Tactics (CT) Scale. In M. A. Straus \& R. J. Gelles (Eds.), Physical violence in American families: Risk factors and adaptations to violence in 8,145 families (pp. 29-47). New Brunswick, NJ: Transaction.

Straus, M. A., \& Gelles, R. J. (1990). Physical violence in American families: Risk factors and adaptations to violence in 8,145 families. New Brunswick, NJ: Transaction.

Straus, M. A., Gelles, R. J., \& Steinmetz, S. K. (1980). Behind closed doors: Violence in the American family. Garden City, NY: Anchor/Doubleday.

Sutherland, C. A., Sullivan, C. M., \& Bybee, D. I. (2001). Effects of intimate partner violence versus poverty on women's health. Violence Against Women, 7, 1122-1143.

Thompson, M. P., Kaslow, N. J., Kingree, J. B., Rashid, A., Puett, R., Jacobs, D., et al. (2000). Partner violence, social support, and distress among inner-city African American women. American Journal of Community Psychology, 28, 127-143.

Tjaden, P., \& Thoennes, N. (2000). Extent, nature, and consequences of intimate partner violence: Findings from the national violence against women survey. Washington, DC: U.S. Department of Justice, Office of Justice Programs, National Institute of Justice.

Tolman, R. M., \& Raphael, J. (2000). A review of research on welfare and domestic violence. Journal of Social Issues, 56, 655681.

Tolman, R. M., \& Rosen, D. (2001). Domestic violence in the lives of women receiving welfare: Mental health, substance 
dependence and economic well-being. Violence Against Women, 7, 141-158.

U.S. General Accounting Office. (2001). Welfare reform: More coordinated federal effort could help states and localities move TANF recipients with impairments towards employment. Washington, DC: Author.

Ware, J. E., \& Sherbourne, C. D. (1992). The MOS 36-item short form health survey (SF-36), I: Conceptual framework and item selection. Medical Care, 30, 473-481.

Weng, H. L. H., Bastian, L. A., Taylor, D. H., Moser, B. K., \& Ostbye, T. (2004). Number of children associated with obesity in middle-aged women and men: Results from the Health and Retirement Study. Journal of Women's Health, 13, 85-91.

Williams, D. R., Takeuchi, D. T., \& Adair, R. K. (1992). Maritalstatus and psychiatric-disorders among blacks and whites. Journal of Health and Social Behavior, 33, 140-157.

World Health Organization. (1997). Composite International Diagnostic Interview (CIDI): Core Version 2.1. Geneva: Author.

Yen, I. H., \& Moss, N. (1999). Unbundling education: A critical discussion of what education confers and how it lowers risk for disease and death. In N. E. Adler, M. Marmot, B. S. McEwen, \& J. Stewart (Eds.), Socioeconomic status and health in industrial nations: Social, psychological and biological pathways (pp. 350351). New York: New York Academy of Science.

Yoshihama, M. (2002). Battered women's coping strategies and psychological distress: Differences by immigration status. American Journal of Community Psychology, 30, 429-452.

Yoshihama, M., \& Gillespie, B. (2002). Age adjustment and recall bias in the analysis of domestic violence data: Methodological improvement through the application of survival analysis methods. Journal of Family Violence, 17, 199-221.

Yoshihama, M., Gillespie, B., Hammock, A. C., Belli, R., \& Tolman, R. (2005). Does the Life History Calendar method facilitate the recall of intimate partner violence?: Comparison of two methods of data collection. Social Work Research, 29, 151163.

Yoshihama, M., \& Horrocks, J. (2003). The relationship between intimate partner violence and PTSD: An application of Cox regression with time-varying covariates. Journal of Traumatic Stress, 16, 371-380. 